\title{
Optimum design of a controlled cable stayed bridge subject to earthquakes
}

\author{
Fernando L. S. Ferreira • Luis M. C. Simoes
}

Received: 1 December 2009 / Revised: 6 December 2010 / Accepted: 20 January 2011 / Published online: 27 February 2011

(C) Springer-Verlag 2011

\begin{abstract}
This paper describes a formulation to optimize the dynamic behavior of an integrated cable-stayed bridge and control strategy system during seismic events. The dynamic analysis uses an analytical solution and accounts for spatial variability, sensor placement and actuator delay. The optimization algorithm deals with model geometry, deck sections and control algorithm as design variables. Control devices were used to improve the dynamic properties and energy dissipation.
\end{abstract}

Keywords Cable-stayed bridges - Structural optimization and control $\cdot$ Seismic hazard $\cdot$ Spatial variability

\section{Introduction}

Long span contemporary cable-stayed bridges are very appealing aesthetically and provide an economical solution for medium to long span bridges. In countries of high seismicity, the structural safety of large structures such as cable-stayed bridges against seismic hazard is a major concern of the design.

The type of connection between the bridge deck and tower is one of the most important design variables that affect the response of cable-stayed bridge. While a rigid connection reduces the displacements of the deck and con-

\section{F. L. S. Ferreira $(\varangle)$}

Department of Civil Engineering, Oporto's Faculty of Engineering, Oporto, Portugal

e-mail: fernando_f2006@portugalmail.pt

\section{M. C. Simoes}

Department of Civil Engineering, University of Coimbra,

Coimbra, Portugal

e-mail: 1csimoes@dec.uc.pt sequently the stresses in the cables, on the other hand it transmits the inertial force of the superstructure to the base of the towers increasing its base shear and bending moment. For this reason researchers have proposed controlled connection devices to improve the dynamic response ( $\mathrm{He}$ and Agrawal 2007; Yang et al. 2004; Dutta et al. 2008; Jung et al. 2003).

If either a spatial model or a structural control strategy are assumed the simplified seismic design procedures (response spectra, equivalent forces, etc) lead to imprecise solutions (EC8-European seismic design code). According to this code, artificial or recorded ground accelerations should be used here.

In cable-stayed bridges the significant tower span results in seismic excitation delay. Bridge's symmetry causes pure longitudinal acceleration to excite only the anti-symmetric modes of vibration. Spatial variability excites the symmetric modes. Traditionally the control design is formulated for a known structure. In this work an integrated structural design and control optimization algorithm will be implemented. This approach allows the researcher to improve the structural performance using geometry, section and control design variables. The physical model is optimized against several seismic events.

The time-history dynamic analysis was carried out using an analytical formulation (Meirovitch 1990). This analytical formulation is the basis for the control algorithm, since it proves to be more accurate and less time consuming for linear dynamic analysis than the traditional numerical methods. The second advantage is that control and dynamic analysis matrices are the same resulting in a more efficient analysis-optimization cycle.

Magaña et al. (1999) propose an innovative control scheme which uses active cables in the bridge. The control is decentralized, meaning that each active cable uses only 
local information (displacement and velocity at anchorage point) to determine actuation. Control force is a linear function of displacement and velocity of the corresponding sensor, which guarantees system stability.

The flexibility of these bridges increases its response when subjected to dynamic loads. The reduction of the dynamic response is of vital importance for their safety and serviceability (Agrawal et al. 2003). In the field of civil engineering many control algorithms and devices have been studied to protect structures against seismic events. Semi-active systems are an attractive alternative for structural vibration reduction due to its mechanical simplicity, low power requirements and large control force capacity (Spencer and Nagarajaiah 2003). Benchmark structural control problems for cable-stayed bridges have allowed researchers to compare the efficiency of control algorithms and devices (Dyke et al. 2003). Linear quadratic regulator control design (LQR) has been shown efficient in reducing the dynamic response of the structure (Jung et al. 2003; Dutta et al. 2008). Other control algorithms such as the $\mathrm{H}_{\infty}$ (Yang et al. 2004) and the optimal polynomial controller (He and Agrawal 2007) have also shown to be effective for structural control.

The optimization of cable-stayed bridges can be stated as that of the minimization of structural cost or volume and the maximum stresses throughout the structure (Hafka and Gurdal 1992; Kirsch 1993). Additional objectives concern deflections or displacements and imposing specified minimum values for the design variables. The work started with shape and sizing optimization by using a two-dimensional (2D) finite element model for the analysis. The problem was extended to three dimensional analysis and the consideration of erection stages under static loading (Simões and Negrão 1994). Seismic events were considered in the optimization by both a spectral and time-history-based procedure (Simões and Negrão 1999). In most of the previous studies, a grid solution was adopted for modeling the deck, with stiffening girders supporting transversal beams, although box girder sections were employed (Simões and Negrão 1999). Prestressing design variables were also considered for the problems of optimal correction of cable forces during erection. Deterministic optimization was enhanced by reliability requirements and formulated within the probabilistic framework of reliability based design (Simões and Negrão 2005).By using control the engineer is allowed to employ different structural systems. Tzan and Pantelides (1996) presented a method for the optimum design of an active frame subject to seismic excitation, with the objective of achieving minimum structure volume with constraints of story drift and stresses. The active frame control algorithm was the instantaneous quadratic optimum control. Khot (1998) proposed an approach to optimally design integrated space systems using multi-objective opti- mization with goals of minimum volume, control force and time to suppress oscillations by using the LQRcontrol scheme. Messac (1998) implemented physical programming to the optimum control of a spacecraft example. The design variables were parameters which determine geometric properties of the structure such as mass, damping and stiffness distribution. Cimellaro et al. (2008) illustrated a two-stage optimization procedure for designing active steel frames, the objective function being a combination of the linear quadratic regulator control and a cost function. In 2009 Cimellaro et al. (2009) extended their work to account for inelastic structures. The technique proved efficient in determining the optimal control/structural system. Ferreira and Simões (2010) applied an integrated optimum control design to a two span cable-stayed footbridge subject to a crowd of joggers during a running event by using one active tendon.

In this paper the cable-stayed bridge design problem is posed in a multi-objective optimization format with goals of minimum cost and stress and a Pareto solution is sought. This problem is equivalent to a minimax formulation which is discontinuous and non-differentiable, both of which attributes make its numerical solution by direct means difficult. An entropy-based technique is used to determine the minimax solution via the minimization of a convex scalar function. This optimization strategy is particularly suitable when a large number of evaluation criteria need to be accounted for.

The proposed optimum design method has been applied to a three-span steel cable-stayed bridge under various seismic events. The significance of dealing with towers height, cable anchor positions on the main girder and pylon as design variables is demonstrated through numerical results showing that considerable performance enhancement can be achieved.

\section{Structural analysis}

A cable-stayed bridge parametric model was implemented in MATLAB using the CALFEM toolbox. The focus of this work was to design a bridge with active controllers for a number of different earthquakes. A $2 d$ elastic model was chosen for the sake of simplicity. The tower, deck and cables were modeled as bar and Bernoulli beam elements. For the calculation of the mass matrix lumped masses method was considered.

Static condensation was implemented in order to reduce the size of the model. In the present work the master degree of freedom (DOF) of the model considered were:

1. The vertical displacements of the deck to maintain the bending of the deck; 


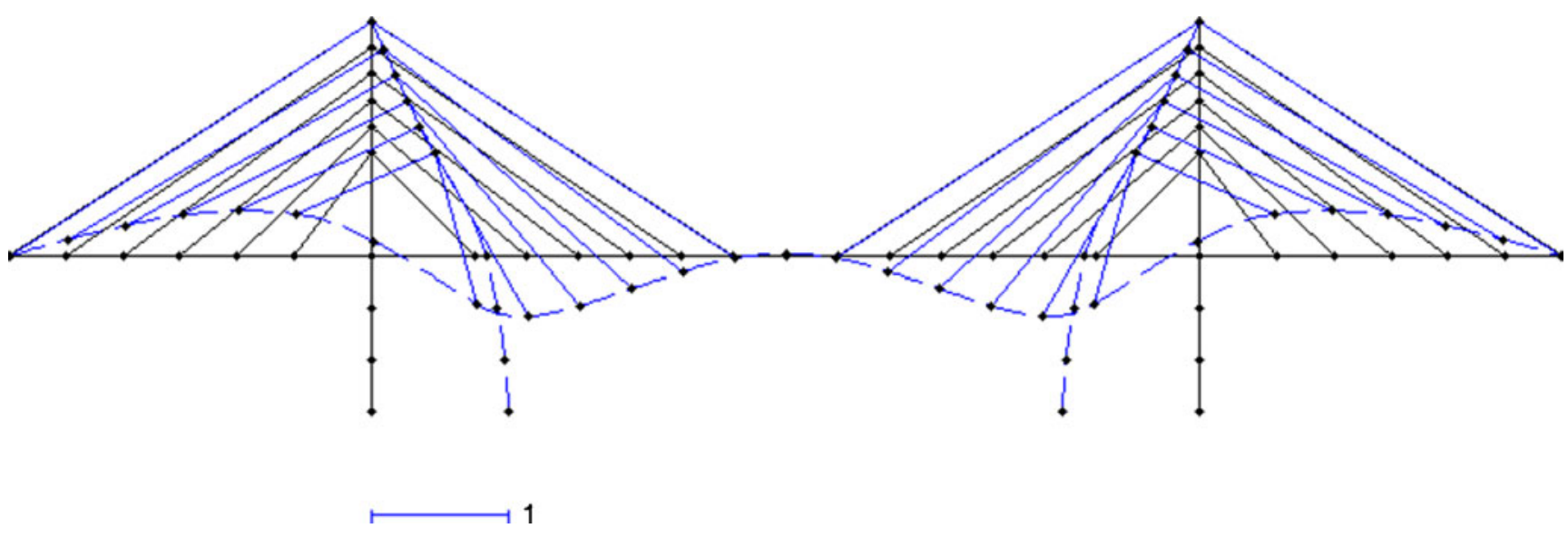

Fig. 1 Structural deformation induced by an unit longitudinal displacement of spatial variability

2. The horizontal displacements of the towers to maintain the bending of the tower;

3. Vertical displacement at the top of each tower to maintain the axial effects;

4. Horizontal displacement of the deck at the lateral supports and midspan to provide information on the deck horizontal movement, maintaining axial properties. Also at the intersection with the towers to keep the DOF where the control devices are placed.

Rayleigh damping is assumed and therefore the previous eigenvalue solution supplies the two lower frequencies. 3\% of critical damping was assigned to the first two modes of vibration.

Wave propagation speed of $2,000 \mathrm{~m} / \mathrm{s}$ was considered to account for spatial variability. It results in a delay of $0.08 \mathrm{~s}$ for the excitation of both piers. Seismic forces $f_{s}$ induced by the seismic acceleration $a(t)$ are determined using the unit structural displacement vector $\boldsymbol{d}_{\boldsymbol{u} \boldsymbol{n}}$ (1). The graphical illustration of the unit displacement can be seen in Fig. 1.

$f_{s}(t)=-M \mathrm{~d}_{\mathrm{un}} \mathrm{a}(\mathrm{t})$

\section{Time-history method}

The direct analytical integration method was considered in the step by step procedure, due to its drastic reduction of computational effort. After the determination of the mass, damping, stiffness matrixes and the force vector $(\boldsymbol{M}, \boldsymbol{C}, \boldsymbol{K}$ and $\boldsymbol{f}$ respectively) the evaluation of the structural response $(\boldsymbol{u})$ needs solving the dynamic equilibrium (2).

$M \ddot{u}+C \dot{u}+K u=f$
The dynamic (2) has an analytical solution (Meirovitch 1990). Considering the state space vector $\boldsymbol{x}$ defined as (3).

$x=\left[\begin{array}{l}u \\ \dot{u}\end{array}\right]$

The 2 nd order equation is replaced by a 1 st order (4)

$\dot{x}=A x+B f$

Where the matrixes $\boldsymbol{A}$ and $\boldsymbol{B}$ are determined by using (5) and (6).

$A=\left[\begin{array}{cc}0 & I \\ -M^{-1} K & -M^{-1} C\end{array}\right]$

$B=\left[\begin{array}{c}0 \\ -M^{-1}\end{array}\right]$

Equation (7) gives the analytical solution to (4) for a given time step $\Delta t$.

$x(t+\Delta t)=e^{\Delta t A} x(t)+\int_{t}^{t+\Delta t} e^{[(t+\Delta t)-\zeta] A} B f(\zeta) d \zeta$

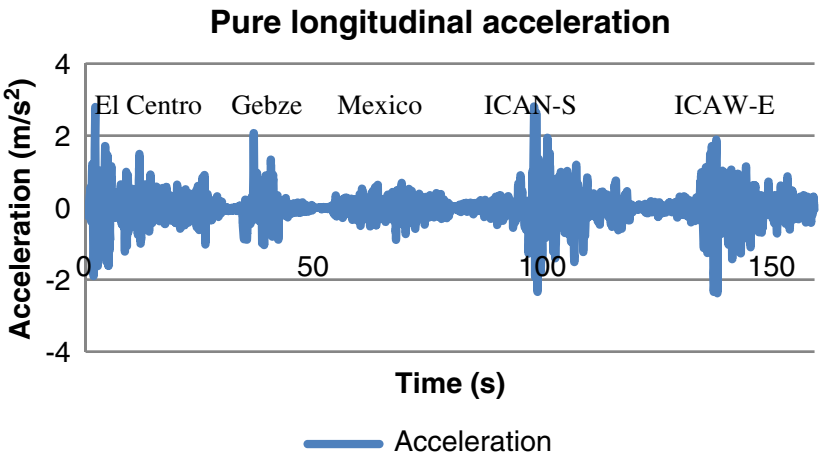

Fig. 2 Time history pure longitudinal acceleration 


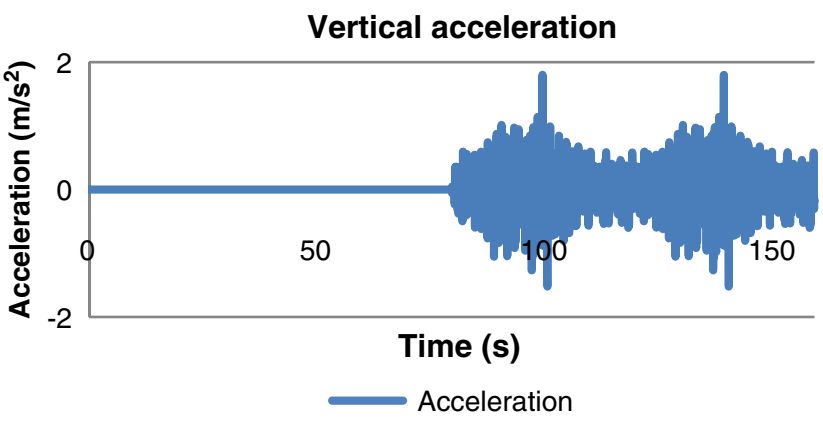

Fig. 3 Time history vertical acceleration

Assuming the forces in the structure vary linearly, dynamic time history analysis can be done using (8).

$x(t+\Delta t)=K_{b} x(t)+K_{f} B f(t)+K_{\Delta f} B[f(t+\Delta t)-f(t)]$

Equation (8) uses information on the time step state, and determines the state in the next time step. The dynamic matrixes $\boldsymbol{K}_{\boldsymbol{b}}, \boldsymbol{K}_{\boldsymbol{f}}$ and $\boldsymbol{K}_{\boldsymbol{\Delta} \boldsymbol{f}}$ are determined using (9), (10) and (11). Where $\boldsymbol{I}$ represents the identity matrix.

$K_{b}=e^{\Delta t A}$

$K_{f}=A^{-1}\left(K_{b}-I\right)$

$K_{\Delta f}=A^{-1}\left(\frac{K_{f}}{\Delta t}-K_{b}\right)$

The time step $\Delta t$ considered was $0.04 \mathrm{~s}$.

The seismic events considered for structural optimization were the ElCentro, Gebze and Mexico City only with the longitudinal ground acceleration plus Ica with both attack angles for longitudinal acceleration (N-S and W-E) simultaneously with the vertical ground acceleration (Figs. 2, 3 and 4).

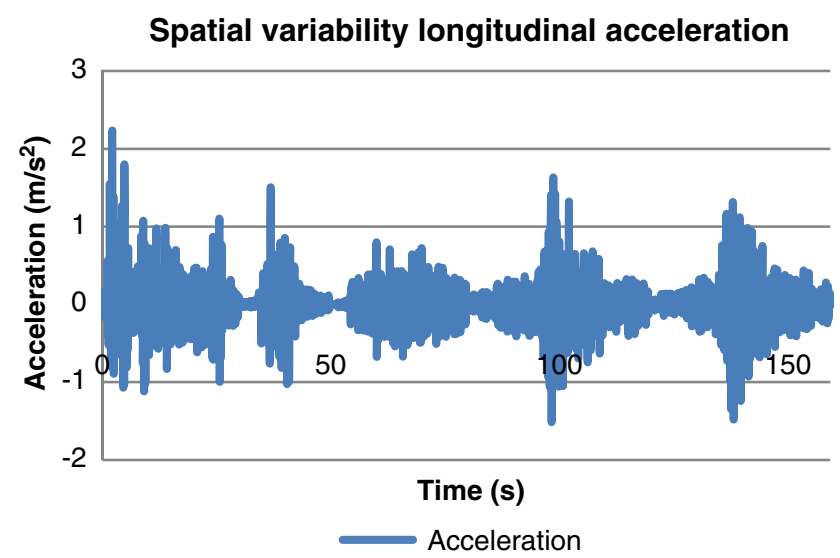

Fig. 4 Time history spatial variability longitudinal acceleration
All these time history events were considered in the structural optimization/control. Each of these earthquakes is associated with a number of goals, their relevance being accounted by providing unbiased probabilities to the entropy based algorithm. According to Shanon's entropy, most of the goals arising from the seismic event are assigned very low probabilities (Jaynes 1957).

\section{Design variables}

The structural response of a cable-stayed bridge is conditioned by a large number of parameters, concerning crosssectional shapes and dimensions, overall bridge geometry, deck to pylon connections, etc. Some of them play only a limited role on the behavior of the bridge while others, such as the cable pattern, tower height and control devices are of major importance for safety purposes.

Three types of design variables were considered: bridge geometry, sectional and control. Geometry refers to the bridge configuration and involves nodal coordinate changes. Sectional refers to cross-sectional variables such as web height, flange width, etc. The control variable is referred in (14).

\section{Control-based optimization}

The controlled system dynamic equilibrium (12) considers the effect of the control $f_{c}$ positioned in the structure by it's corresponding vector of unitary force $\boldsymbol{F}_{\boldsymbol{u}}$ and the seismic disturbance forces $w$.

$\dot{x}=A x+B F_{u n} f_{c}+B w$

The control scheme utilized was the linear quadratic regulator (LQR). It has proven to be very effective in the literature and by being convex and continuous is suitable to integrated structural/control design. The objective is to determine the optimal feedback matrix which minimizes the performance index $J\left(f_{c}\right)(13)$.

$J\left(f_{c}\right)=\int_{0}^{\infty} x^{T} Q x+f_{c}^{T} R f_{c} d t$

The weighting matrix $\mathbf{R}=[2 \times 2]$ is an identity matrix and $\mathbf{Q}$ is such that the first term relates to the system mechanical energy (14), " $\alpha$ " is the control optimization parameter. If " $\alpha$ " is a low value weak control forces will be generated.

$Q=\alpha\left[\begin{array}{cc}K & 0 \\ 0 & M\end{array}\right]$

It was the author's option that the weighting matrices had a physical meaning. The system mechanic energy $\left(E_{\text {mec }}\right)$ 


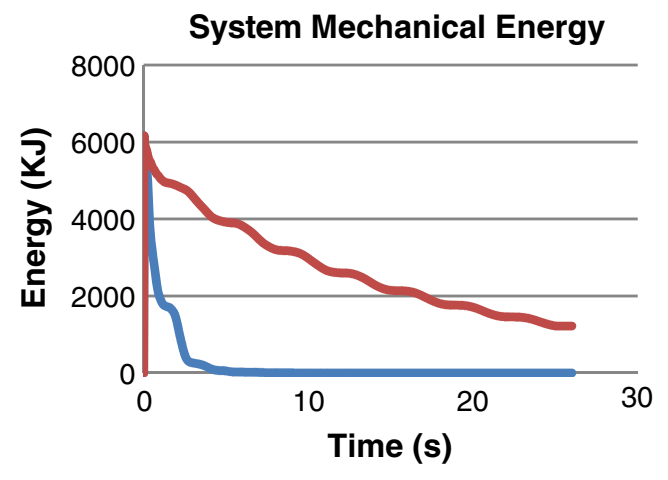

With Control Without Control

Fig. 5 Control system performances when subjected to a delta Dirac longitudinal acceleration

can be determined by the sum of the kinetic and the elastic energy (15). The system stresses can be related to the system elastic energy. Apart from the damping effects the kinetic transforms itself in elastic energy. The objective of the controller was to keep the system mechanical energy as small as possible in order to reduce the stresses.

$E_{\mathrm{mec}}=\frac{1}{2}\left(u^{T} K u+\dot{u}^{T} M \dot{u}\right)$

Then the first term of the LQR control law relates with system mechanic energy (16).

$x^{T} Q x=2 \alpha E_{\text {mec }}$

The optimal feedback matrix was determined using the MATLAB (2008) routine lqr.m within the control toolbox. The control force $f_{c}$ can be determined using (17).

$f_{c}=-R^{-1}\left(B F_{u n}\right)^{T} S x$

Where $\mathbf{S}=$ solution of the algebraic Riccati (18) (Meirovitch 1990).

$S A^{T}+S A-S\left(B F_{u n}\right) R^{-1}\left(B F_{u n}\right)^{T} S+Q=\dot{S}$

The control system performance is tested using a delta Dirac longitudinal base acceleration (Fig. 5).

\section{Sensor and delay}

The determination of the control force by (17) needs information on the state space vector $\boldsymbol{x}$. The system information is not entirely available. The problem now posed is how to obtain the best estimation for the state space vector $\boldsymbol{x}$ based on the sensor information $\boldsymbol{x}_{\text {sens }}$ (19).

$\mathrm{x}_{\text {sens }}=\left[\begin{array}{c}u_{\text {sens }} \\ \dot{u}_{\text {sens }}\end{array}\right]$

The modal transformation is presented in (20), $\Phi$ being the eigen-mode matrix and $\boldsymbol{q}$ the modal vector.

$u=\Phi q$

The sensors are placed at location " $s$ ". Considering that the system can be well observed if one has the information about " $\boldsymbol{n}$ " modes of vibration. The (21) formulates the problem.

$\left[\begin{array}{cc}\phi_{\mathrm{n}}^{\mathrm{s}} & 0 \\ 0 & \phi_{\mathrm{n}}^{\mathrm{s}}\end{array}\right]\left[\begin{array}{c}q_{n} \\ \dot{q}_{n}\end{array}\right]=\mathrm{x}_{\mathrm{sens}}$

In this work the number of modes of interest is superior to the number of sensors so (21) is solved using a minimum quadratic formulation (22).

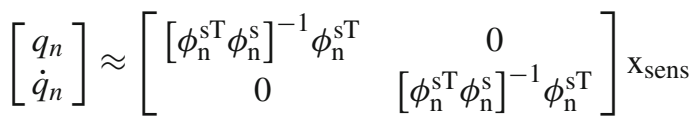

The state space vector can be estimated using (23).

$\mathrm{x}=\left[\begin{array}{cc}\phi_{\mathrm{n}} & 0 \\ 0 & \phi_{\mathrm{n}}\end{array}\right]\left[\begin{array}{c}q_{n} \\ \dot{q}_{n}\end{array}\right] \approx \Phi_{\text {filter }}^{\mathrm{n}} \mathrm{x}_{\text {sens }}$

$\Phi_{\text {filter }}^{\mathrm{n}}$ represents the filter matrix which transforms the sensor in state space information (24).

$\Phi_{\text {filter }}^{\mathrm{n}}=\left[\begin{array}{cc}\Phi_{\mathrm{n}}\left[\phi_{\mathrm{n}}^{\mathrm{sT}} \phi_{\mathrm{n}}^{\mathrm{s}}\right]^{-1} \phi_{\mathrm{n}}^{\mathrm{sT}} & 0 \\ 0 & \Phi_{\mathrm{n}}\left[\phi_{\mathrm{n}}^{\mathrm{sT}} \phi_{\mathrm{n}}^{\mathrm{s}}\right]^{-1} \phi_{\mathrm{n}}^{\mathrm{sT}}\end{array}\right]$

To account to the system delay ( $\left.\Delta t_{\text {delay }}\right)$ a state-space prevision is considered as in the time history analysis section (25 and 26).

$x\left(t+\Delta t_{\text {delay }}\right)=K_{b_{\text {delay }}} x(t)$

$K_{b_{\text {delay }}}=e^{\Delta t_{\text {delay } A}}$

\section{Optimization strategy and sensitivity analysis}

The objective of this work is to find the least cost solution while keeping the whole structure in the elastic range throughout the seismic event.

Control-based design benchmark problems define the performance of some objectives to be met (Dyke et al. 
2003). Peak stresses in the critical sections, their corresponding scaled values, maximum displacements at critical sections, maximum control force, power required for control, etc. Considering $\mathrm{J}_{\mathrm{i}}$ as the $i^{\text {th }}$ evaluation criteria, the optimization problem can then be formulated (27a and $27 \mathrm{~b}$ ).

Minimize Cost

st $J_{i} \leq J_{\text {imax }}$ or $\frac{J_{i}}{J_{\text {imax }}}-1 \leq 0$

The objective is to find the design variables which minimize all the goals. This is achieved by the minimax optimization problem (28).

$\min _{\bar{v}} \max _{i}\left\{\frac{J_{i}}{J_{\text {imax }}}-1, \frac{\text { Cost }}{\mathrm{C}_{\mathrm{ref}}}-1\right\}$

In minimization problems, a solution vector is said to be Pareto optimal if no other feasible vector exists that could decrease one objective function without increasing at least another one. The optimum vector usually exists in practical terms and is not unique (Simões and Templeman 1989). The minimax problem (28) is equivalent to the optimization problem $(27 \mathrm{a}$ and $27 \mathrm{~b})$ if the reference cost $\left(\mathrm{C}_{\mathrm{ref}}\right)$ is continuously updated throughout the optimization process. The minimax problem is discontinuous and non-differentiable, these attributes making difficult its numerical solution by direct means.

There is a huge number of objectives arising from the time history of the seismic event, these objectives being generally not known implicitly. The objectives were cast according to the minimum entropy principle. The problem can be formulated as a Kreisselmeyer-Stainhauser scalar function (Simões and Templeman 1989). This form leads to a convex approximation of the objective and constraint boundaries (29). Accuracy increases with $\rho$.

$$
\begin{aligned}
\operatorname{Minimize} \frac{1}{\rho} \ln [ & \sum_{\mathrm{t}=0}^{\mathrm{T}} \exp \left(\rho\left(J_{\text {util }}(\mathrm{t}, \bar{v})-1\right)\right) \\
& \left.+\exp \left(\rho J_{\text {cost }}(\bar{v})\right)\right]
\end{aligned}
$$

$J_{\text {util }}$ is defined as the structure time history global utilization factor. When $\rho$ increases $J_{\text {util }}$ converges to the maximum quotient between the sections stress and elastic limit (30). The determination of $\mathrm{J}_{\mathrm{util}}$ considers all the 9 evaluation criteria, their maximum and minimum limit values $\left(\mathrm{J}_{\mathrm{imax}}\right.$ and $\left.\mathrm{J}_{\text {imin }}\right)$. $J_{u t i l}$ is dependent of the design variable vector $(\overline{\boldsymbol{v}})$.

$$
\begin{aligned}
J_{\text {util }}(t, \bar{v})= & \frac{1}{\rho} \ln \sum_{\mathrm{i}=1}^{\mathrm{n}} \exp \left[\rho\left(\frac{J_{i}(t, \bar{v})}{J_{\text {imax }}}-1\right)\right] \\
& +\exp \left[\rho\left(\frac{J_{i}(t, \bar{v})}{J_{\text {imin }}}-1\right)\right]+1
\end{aligned}
$$

As stated above the cost function (31) must be improved in relation to a reference cost $C_{\text {ref }}$. In the optimization cycle $C_{r e f}$ refers to the initial solution. After the structural safety is guaranteed $\left(\operatorname{Max}\left(\mathrm{J}_{\mathrm{util}}\right)<1\right)$ the algorithm aims at improving the structural cost and $C_{\text {ref }}$ updates to the last solution.

$J_{\text {cost }}(\bar{v})=\frac{\operatorname{Cos} t(\bar{v})}{\mathrm{C}_{\mathrm{ref}}}-1$

The sensitivity analysis was performed using the finite difference method, no direct programming of stiffness and mass matrix partial derivates were needed.

The strategy adopted was to solve an iterative sequence of explicit approximation problems. This problem has an analytical solution giving the design variable changes. Solving for particular numerical values of the objectives forms

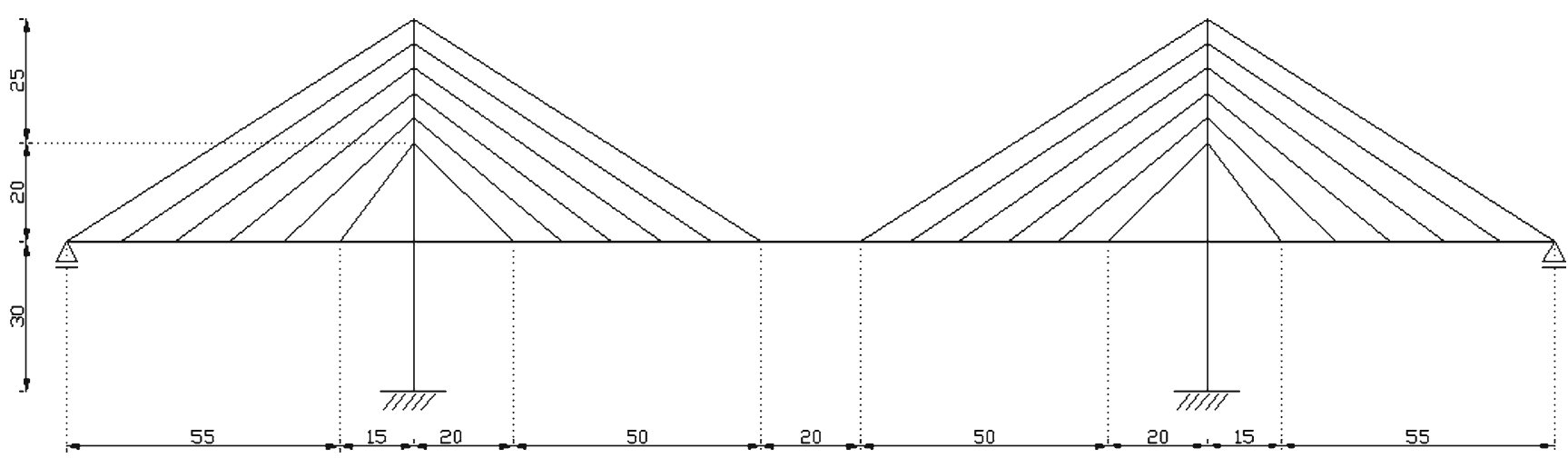

Fig. 6 Initial model geometry 


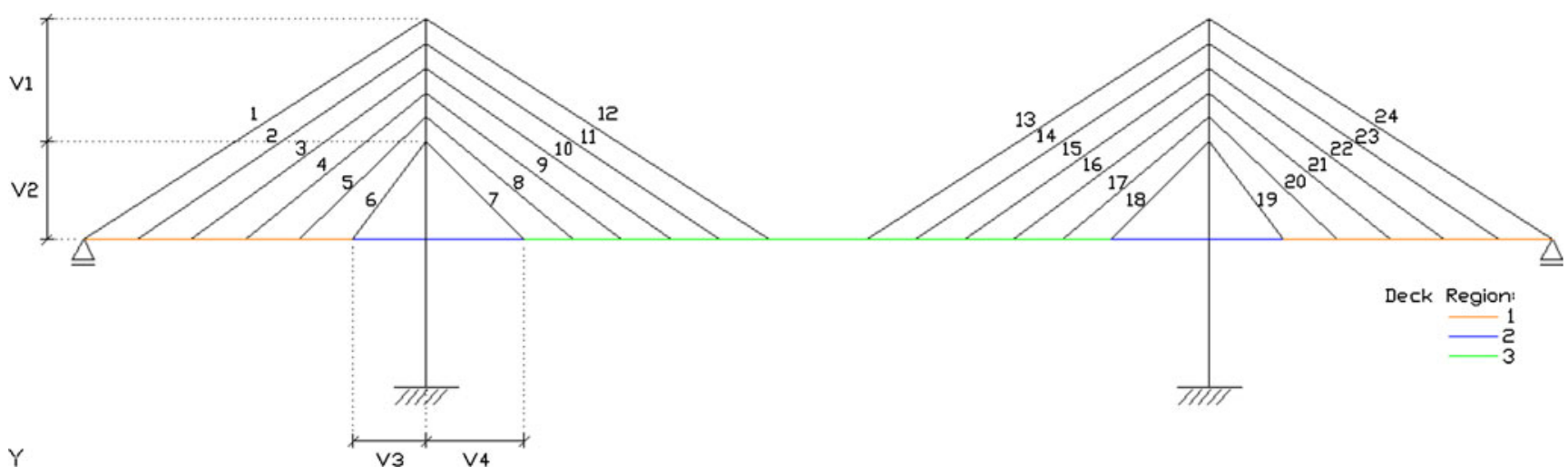

Fig. 7 Deck regions and cable numbering

one iteration of the complete solution of problem. The solution vector of such iteration represents a new design which needs to be analyzed and checked for feasibility. Iterations continue until changes in the design variables become small. During the iteration the control parameter $\rho$ must be increased to ensure that a minimax optimum solution is found. The optimization algorithm is solved by the conjugated gradient algorithm (32 and 33).

$\bar{v}_{\mathrm{i}+1}=\bar{v}_{\mathrm{i}}+\lambda \times \mathrm{S}_{\mathrm{i}}$

$\mathrm{S}_{\mathrm{i}}=-\nabla \mathrm{FO}_{\mathrm{i}}+\left(\frac{\left\|\nabla \mathrm{FO}_{\mathrm{i}-1}\right\|}{\left\|\nabla \mathrm{FO}_{\mathrm{i}}\right\|}\right)^{2} \times \mathrm{S}_{\mathrm{i}-1}$

\section{Numerical example}

\subsection{Problem formulation}

These strategy possibilities are shown in the numerical example presented in this section. The initial solution is shown in Fig. 6 corresponding to a symmetric long span cable-stayed bridge.

Tower positioning and total span is considered to be known. Cable anchor positions are considered to remain evenly spaced in Region 1 and 3 (Fig. 7). A total of 37 design variables of sizing, shape and control were considered, as shown in Tables 1 and 2 and Figs. 7, 8 and 9.

The material cost factor was considered 1 for deck, 1.4 for tower and 1.8 for cable steel. The steel yield stress was assigned $500 \mathrm{MPa}$ for cables and $300 \mathrm{MPa}$ for deck and tower. The Young modulus for the stays in the analysis is the secant Ernst value and is considered to be $200 \mathrm{GPa}$. A structural mass of $12,000 \mathrm{~kg} / \mathrm{m}$ was added on the deck. The problem evaluation criteria considered in this work is given in Table 3. This evaluation criteria were imposed to keep the whole structure in elastic range, therefore the elastic limit
Table 1 Problem design variables

\begin{tabular}{lll}
\hline Variable & Type & Reference \\
\hline V1-V4 & Model geometry & Figure 7 \\
V5 & Control & $(14)$ \\
V6-V17 & Deck cross sections & Figure 8 \\
V18-V25 & Tower cross sections & Figure 9 \\
V26-V37 & Cable areas & Table 3 \\
\hline
\end{tabular}

Table 2 Cable areas design variables

\begin{tabular}{lc}
\hline Variable & Cable no. \\
\hline V26 & 1.24 \\
V27 & 2.23 \\
V28 & 3.22 \\
V29 & 4.21 \\
V30 & 5.20 \\
V31 & 6.19 \\
V32 & 7.18 \\
V33 & 8.17 \\
V34 & 9.16 \\
V35 & 10.15 \\
V36 & 11.14 \\
V37 & 12.13 \\
\hline
\end{tabular}
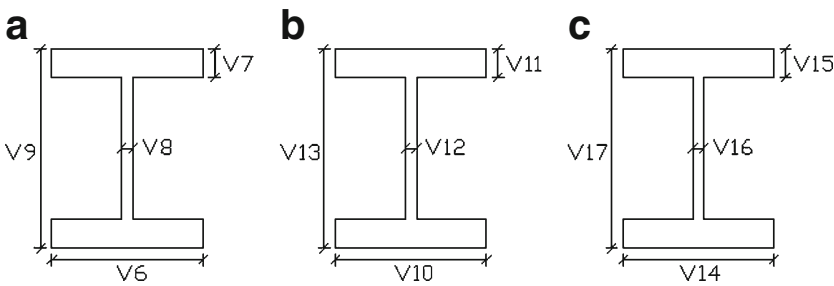

Fig. 8 Deck sizing design variables a region 1, b region 2 , c region 3 


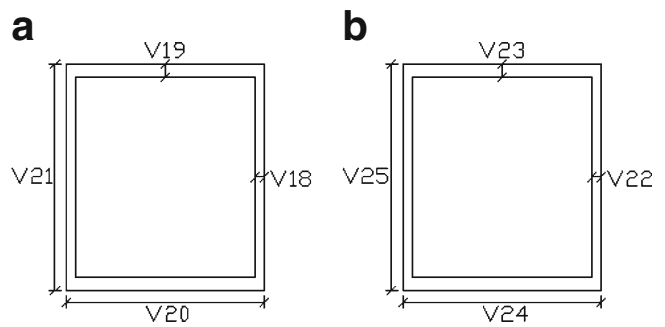

Fig. 9 Tower's sizing design variables a below deck, $\mathbf{b}$ above deck

Table 3 Problem evaluation criteria

Designation

\begin{tabular}{ll}
\hline J1 & Maximum base shear in the towers \\
J2 & Maximum shear at the deck level in the towers \\
J3 & Maximum moment at the base of the towers \\
J4 & Maximum moment at the deck level of the towers \\
J5 & Maximum horizontal deck displacement \\
J6 & Maximum force generated by the control devices \\
J7 & Shear in the deck \\
J8 & Moment in the deck \\
J9 & \\
J10 &
\end{tabular}

Table 4 Problem evaluation criteria limit

\begin{tabular}{ll}
\hline & Designation \\
\hline J1-J4 max & Moment and shear elastic limit \\
J5 max & $30 \%$ of the yield stress \\
J6 max & $0.3 \mathrm{~m}$ \\
J7 max & $5,000 \mathrm{kN}$ \\
J8 max & $50 \%$ EC3 buckling curve a \\
J9-J10 max & Moment and shear elastic limit \\
\hline
\end{tabular}

cannot be reached, the cables must maintain a minimum tension as compression is undesirable (Table 4). Devices were placed in the tower-deck horizontal connection. This is an efficient position to reduce the response of the first anti-symmetric modes due to their significant displacement.

The actuators employed are ideal semi-active devices, this meaning the control forces found in (16) must be dissipative, otherwise null. No restraint was considered in the tower-deck vertical direction.

The sensors were placed at know locations. Since the geometry of the structure is changing in the optimization process, the sensors were positioned at the nodes where it is expected to obtain greater modal deformation. Displacement and velocity are known at these locations (Fig. 10).

Three anti-symmetric lower modes were considered for the state space estimate because they are the most excited by the seismic event.

\subsection{Optimization results}

The optimization strategy cycle was repeated until convergence. Multi start procedure was employed given the nonconvex behaviour and possibly nonconnected domain. Figures 11 and 12 show the structural stress and cost improvement resume. It can be seen that after 8 iterations all the critical sections are kept in the elastic range throughout the seismic event and the total cost is decreased. A $29 \%$ cost reduction and $47 \%$ utilization factor was achieved. The results use the steepest descent algorithm as it proved to converge faster.

In the first two iterations the model geometry changes drastically, improving the structural system and dynamic properties. The total cost reduces in further iteration by selecting least cost cross sections.

The initial and final design variable values can be seen in Table 5 and the final bridge geometry is presented in Fig. 13.

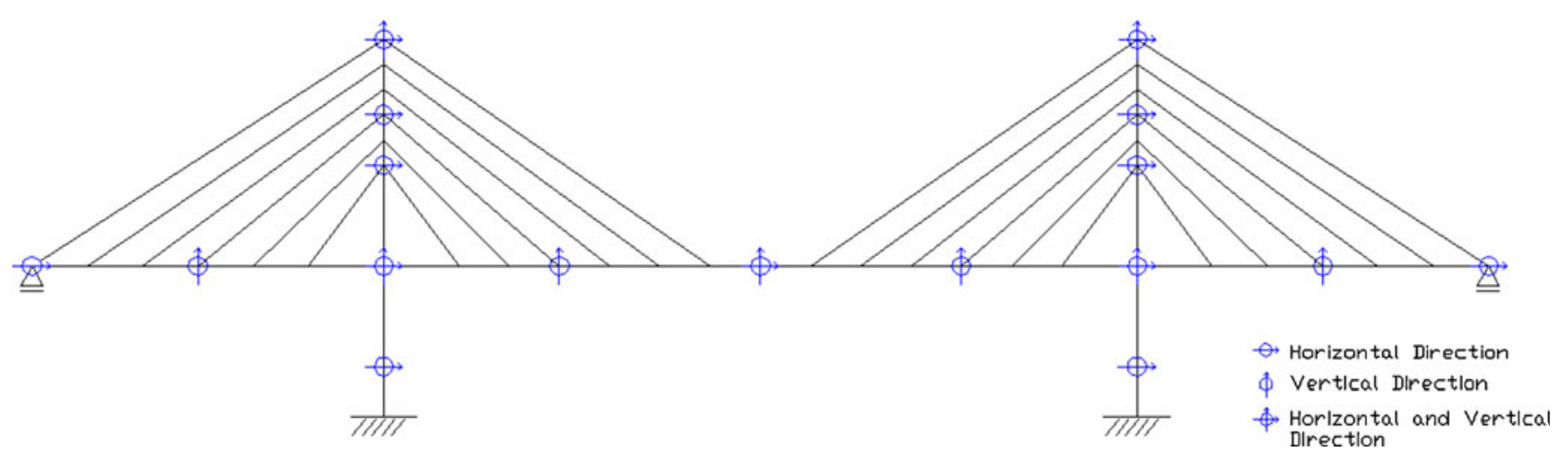

Fig. 10 Displacement and velocity sensors nodal localization 


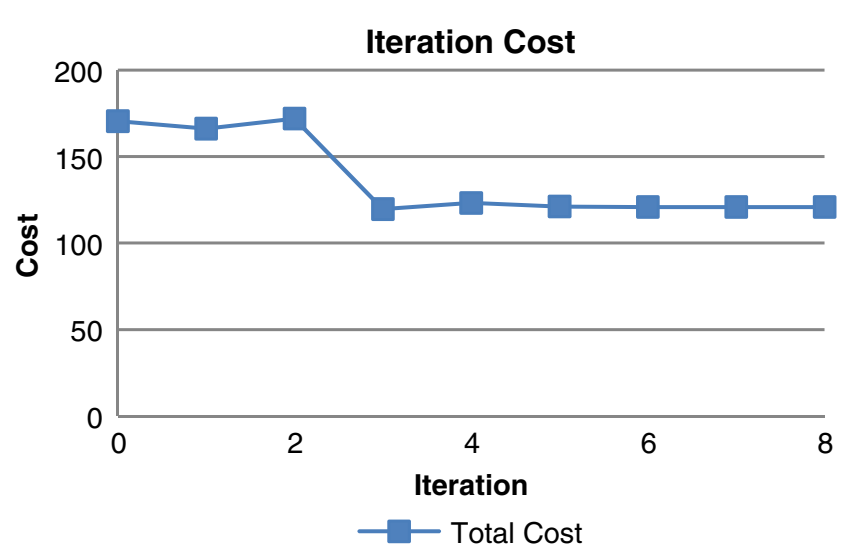

Fig. 11 Cost evolution during optimization

The first two design variables accounts for the tower geometry and cable position. Their final values justify the choice of a fan solution.

Design variables V3 and V4 account to the 6th and 7th cable anchor position. Their variation decreased the length of the deck Region 1 and increased Region 3 which has smaller sections and lower cost. These variables are also closely related to the cable's tension distribution which is much more efficient than in the initial solution (Fig. 14).

Control design variable V5 increased $10 \%$. This is interesting because control forces limit was exceeded by $18 \%$ in the initial solution (Table 6). Increasing the control parameter would mean an increase in the control effort. However in the optimized solution peak control forces decreased (Fig. 15). This shows that the control was more efficient in the optimized solution.

Deck cross sections (V6-V17) reduce to their lower limits. However, deck shear and bending utilization factor decreased. Consequently a lower structural cost was obtained.

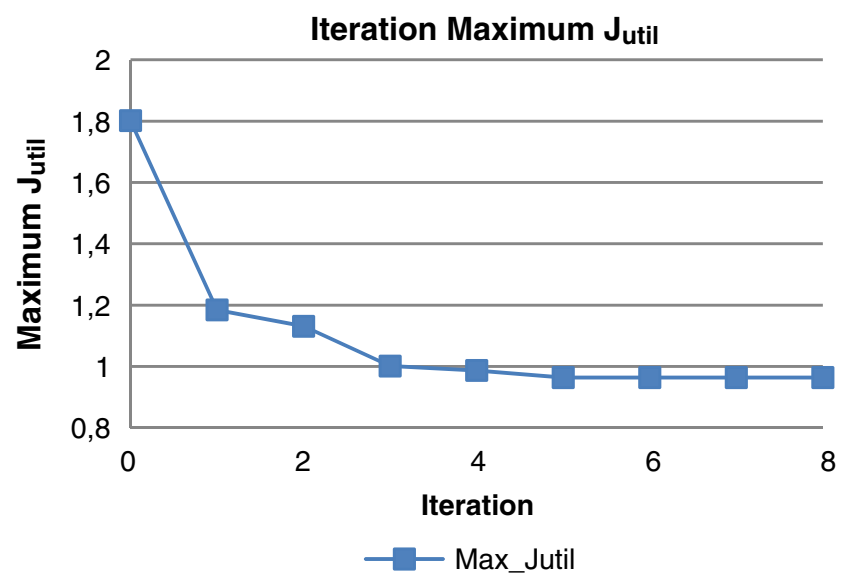

Fig. 12 Utilization factor evolution during optimization
Table 5 Design variables start, minimum, maximum and optimized values

\begin{tabular}{|c|c|c|c|c|c|}
\hline Units & $\begin{array}{l}\text { Design } \\
\text { variable }\end{array}$ & $\begin{array}{l}\text { Starting } \\
\text { value }\end{array}$ & $\begin{array}{l}\text { Minimum } \\
\text { value }\end{array}$ & $\begin{array}{l}\text { Maximum } \\
\text { value }\end{array}$ & $\begin{array}{l}\text { Optimized } \\
\text { value }\end{array}$ \\
\hline $\mathrm{m}$ & V1 & 25.0 & 2.5 & 37.5 & 6.3 \\
\hline $\mathrm{m}$ & $\mathrm{V} 2$ & 20.0 & 2.0 & 40.0 & 32.3 \\
\hline $\mathrm{m}$ & V3 & 15.0 & 7.5 & 22.5 & 21.0 \\
\hline $\mathrm{m}$ & V4 & 20.0 & 10.0 & 30.0 & 16.2 \\
\hline $\mathrm{m} / \mathrm{kN}$ & V5 & 10,000 & 5,000 & 15,000 & 11,028 \\
\hline $\mathrm{m}$ & V6 & 0.985 & 0.886 & 1.378 & 0.894 \\
\hline $\mathrm{m}$ & V7 & 0.018 & 0.016 & 0.025 & 0.017 \\
\hline $\mathrm{m}$ & V8 & 0.030 & 0.027 & 0.042 & 0.027 \\
\hline $\mathrm{m}$ & V9 & 4.000 & 3.600 & 5.600 & 3.600 \\
\hline $\mathrm{m}$ & V10 & 1.000 & 0.900 & 1.400 & 0.900 \\
\hline $\mathrm{m}$ & V11 & 0.024 & 0.022 & 0.034 & 0.022 \\
\hline $\mathrm{m}$ & V12 & 0.033 & 0.030 & 0.046 & 0.030 \\
\hline $\mathrm{m}$ & V13 & 2.539 & 2.285 & 3.555 & 2.285 \\
\hline $\mathrm{m}$ & V14 & 0.998 & 0.898 & 1.397 & 0.898 \\
\hline $\mathrm{m}$ & V15 & 0.015 & 0.014 & 0.021 & 0.014 \\
\hline $\mathrm{m}$ & V16 & 0.015 & 0.014 & 0.021 & 0.014 \\
\hline $\mathrm{m}$ & V17 & 1.000 & 0.900 & 1.400 & 0.900 \\
\hline $\mathrm{m}$ & V18 & 0.017 & 0.012 & 0.024 & 0.012 \\
\hline $\mathrm{m}$ & V19 & 0.015 & 0.011 & 0.021 & 0.011 \\
\hline $\mathrm{m}$ & V20 & 3.656 & 2.559 & 5.118 & 2.559 \\
\hline $\mathrm{m}$ & V21 & 5.000 & 3.500 & 7.000 & 5.114 \\
\hline $\mathrm{m}$ & V22 & 0.015 & 0.011 & 0.021 & 0.012 \\
\hline $\mathrm{m}$ & V23 & 0.015 & 0.011 & 0.021 & 0.015 \\
\hline $\mathrm{m}$ & V24 & 2.779 & 1.945 & 3.891 & 1.967 \\
\hline $\mathrm{m}$ & V25 & 2.000 & 1.400 & 2.800 & 1.400 \\
\hline $\mathrm{cm}^{2}$ & V26 & 112.0 & 89.6 & 156.8 & 89.6 \\
\hline $\mathrm{cm}^{2}$ & V27 & 27.0 & 21.6 & 37.8 & 25.5 \\
\hline $\mathrm{cm}^{2}$ & V28 & 25.0 & 20 & 35 & 20.0 \\
\hline $\mathrm{cm}^{2}$ & V29 & 43.0 & 34.4 & 60.2 & 34.4 \\
\hline $\mathrm{cm}^{2}$ & V30 & 49.0 & 39.2 & 68.6 & 39.2 \\
\hline $\mathrm{cm}^{2}$ & V31 & 81.0 & 64.8 & 113.4 & 64.8 \\
\hline $\mathrm{cm}^{2}$ & V32 & 43.0 & 34.4 & 60.2 & 34.4 \\
\hline $\mathrm{cm}^{2}$ & V33 & 40.0 & 32 & 56 & 32.0 \\
\hline $\mathrm{cm}^{2}$ & V34 & 33.0 & 26.4 & 46.2 & 26.4 \\
\hline $\mathrm{cm}^{2}$ & V35 & 53.0 & 42.4 & 74.2 & 50.2 \\
\hline $\mathrm{cm}^{2}$ & V36 & 27.0 & 21.6 & 37.8 & 22.0 \\
\hline $\mathrm{cm}^{2}$ & V37 & 77.0 & 61.6 & 107.8 & 61.6 \\
\hline
\end{tabular}

Tower cross sections (V18-V25) become close to their lower limit. Base tower section height (V21) is an exception and is increased. Bending moment (J3) is highly sensible to this variable changes. A decrease of $1 \%$ in V21 would mean an increase of $6 \%$ in the bending moment peak stress.

Cable areas were also reduced to the minimum established value with three interesting exception. Cables 2-23 


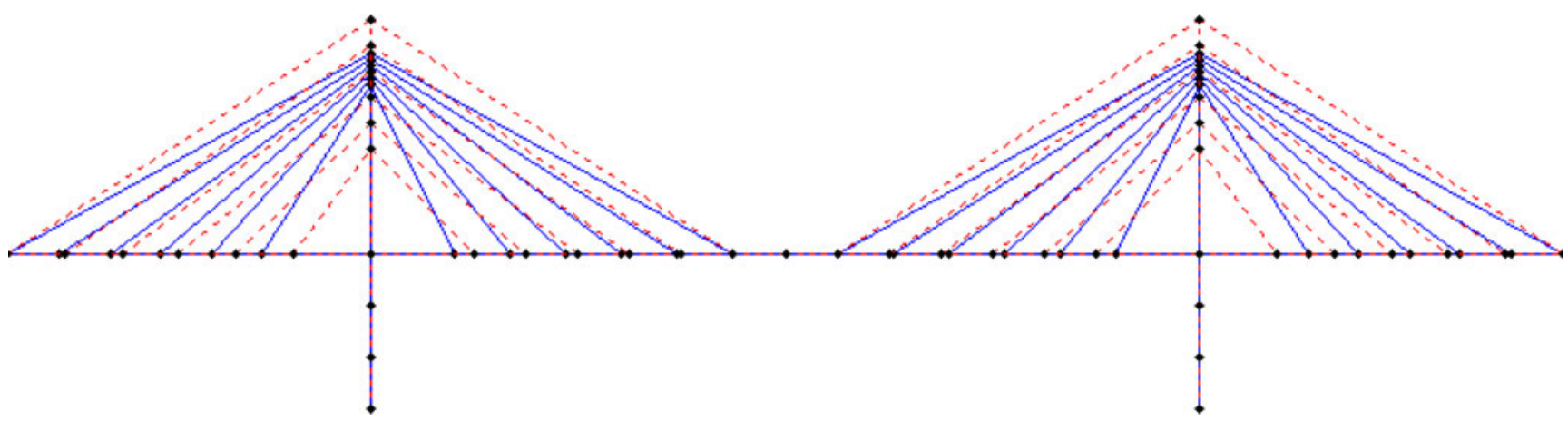

Fig. 13 Initial (red) and optimized geometry (blue)

(V27), Cables 10-15 (V35) and cables 11-14 (V36). A variation in these design variables would deteriorate base bending moment (J3) maximum value and/or cables maximum tension (J5) which constraint the design.

Evaluation criteria maximum utilization factor can be seen in Table 6.

The tower's stresses (J1-J4) increased in the optimized solution with the exception of base shear (J1). Base bending moment (J3) conditions the design, having a utilization factor near 1 . This is caused by the base tower cross section reduction.

Tower's buckling above the deck (J8) increased as a consequence of the increase of the buckling length (V2) and cross section reduction.

Maximum horizontal displacement of the deck (J6) was decreased by $6 \%$.

The initial solution violated the maximum stresses in cables 6-19 and 7-18 (Fig. 15). J5 was the most critical design criteria, exceeding the maximum by $80 \%$ in cables 7 and 18. In the optimized structure the cables tension distribution is more efficient and is kept within the allowable limits. It is interesting to note that in cables 7 and 18 cross section (V32) is reduced to its lower limit, which could result to a stress increase. This however did not happen

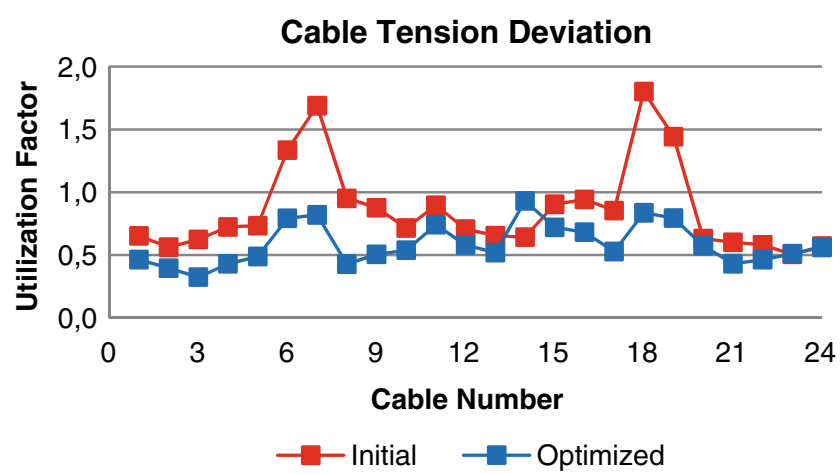

Fig. 14 Initial (red) and optimized cable tension deviation (blue) showing that the optimized geometry stress distribution is quite efficient.

Deck moment and shear stresses were not critical for the design. However there was a cross sectional reduction, shear (J9) decreased 30\% and bending (J10) 40\%. The bending and shear stresses envelope can be seen in Figs. 16 and 17, respectively.

From the results, the overall structural performance was shown to be improved. Lower cost was achieved and the structural safety is higher. This shows that the seismic amplification was reduced and that a more efficient structural system was found. Time history of utilization factor $\mathrm{J}_{\text {util }}$ can be seen in Fig. 18. It is shown that the response reduced mostly in Ica N-S and Ica E-O events. The optimization cycle aimed to improve the bridge dynamic behavior for Ica. This was the critical scenario in the controlled structure.

It still needs to be clarified, whether or not the optimum structural system is dependent on the utilization of the control strategy. A dynamic analysis was conducted using initial and optimized geometry without control. This analysis $\mathrm{J}_{\mathrm{util}}$ conclusion can be seen in Fig. 19.

Table 6 Evaluation criteria start and optimized values

\begin{tabular}{lllc}
\hline & Initial solution & Optimized solution & Variation (\%) \\
\hline $\mathrm{J}_{\text {util }} 1$ & 0.208 & 0.190 & -8.7 \\
$\mathrm{~J}_{\text {util }} 2$ & 0.535 & 0.671 & 25.4 \\
$\mathrm{~J}_{\text {util }} 3$ & 0.887 & 0.959 & 8.1 \\
$\mathrm{~J}_{\text {util }} 4$ & 0.443 & 0.469 & 6.0 \\
$\mathrm{~J}_{\text {util }} 5$ & 1.802 & 0.931 & -48.3 \\
$\mathrm{~J}_{\text {util }} 6$ & 0.890 & 0.832 & -6.6 \\
$\mathrm{~J}_{\text {util }} 7$ & 1.183 & 0.960 & -18.8 \\
$\mathrm{~J}_{\text {util }} 8$ & 0.207 & 0.340 & 64.4 \\
$\mathrm{~J}_{\text {util }} 9$ & 0.141 & 0.096 & -31.9 \\
$\mathrm{~J}_{\text {util }} 10$ & 0.535 & 0.318 & -40.6 \\
$\mathrm{~J}_{\text {util }}$ & 1.802 & 0.964 & -46.5 \\
Cost & 170.5 & 120.9 & -29.1 \\
\hline
\end{tabular}


Fig. 15 Time history control force

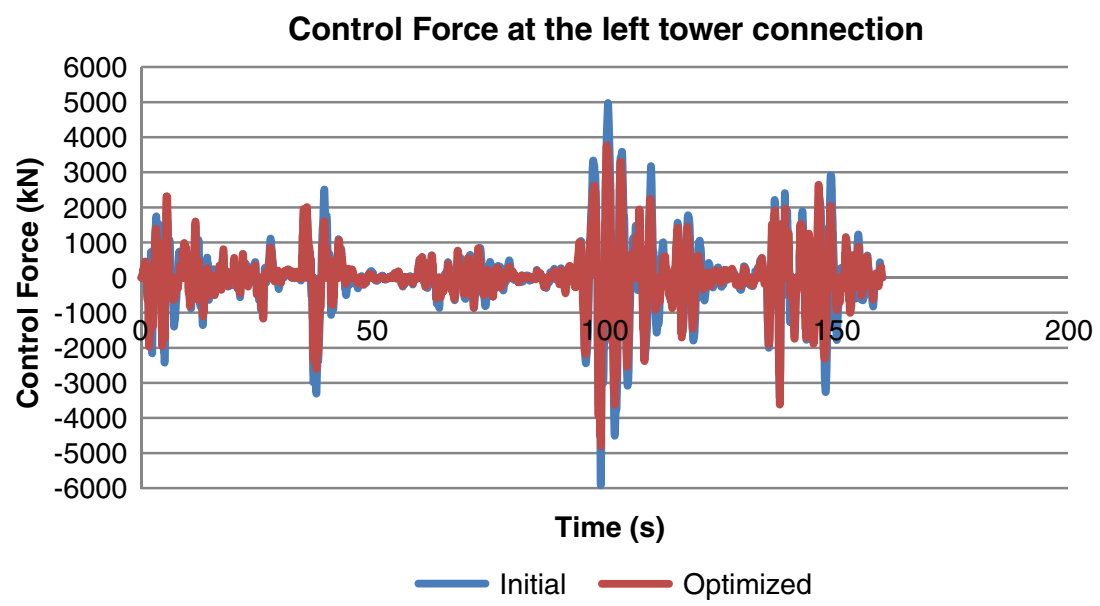

It can be seen that the optimized system behaves worse than the initial solution. The maximum utilization factor increases from 2.6 in the initial to 3.6 in the final geometry.

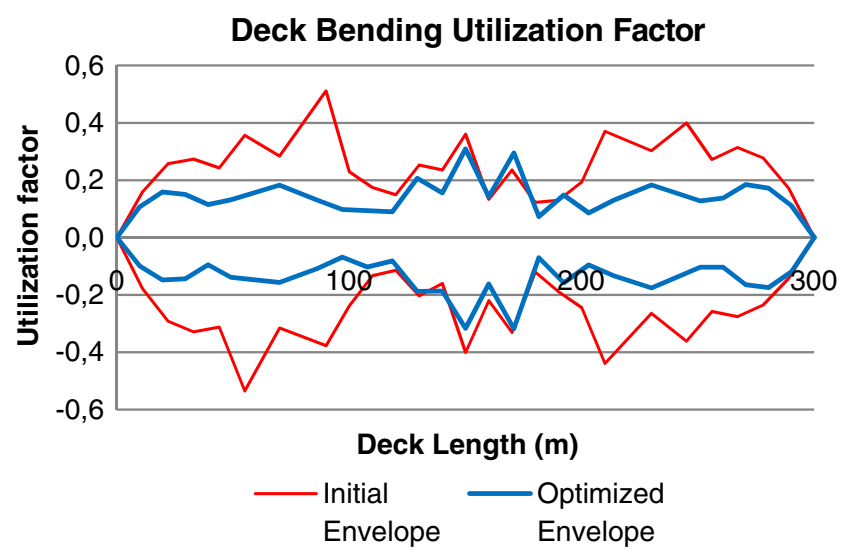

Fig. 16 Initial (red) and optimized bending envelope (blue)

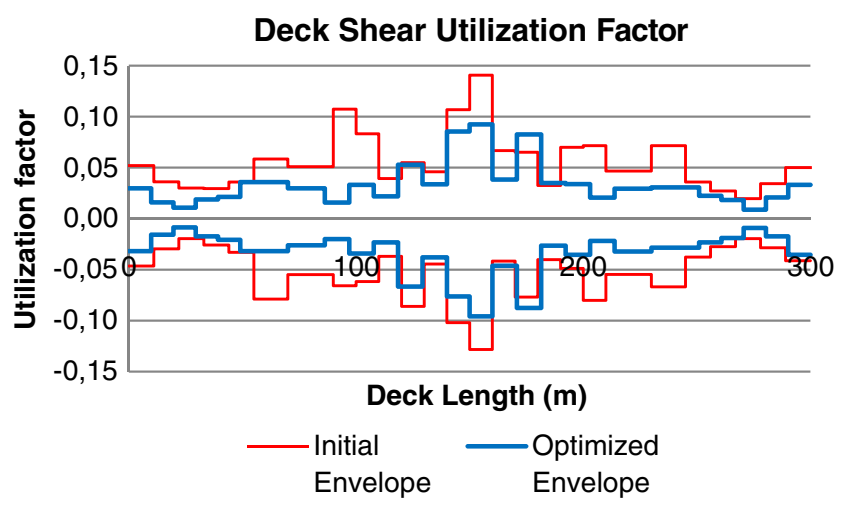

Fig. 17 Initial (red) and optimized shear envelope (blue)
These results show the optimum design changes if the control devices are not used. Separate structural and control design is not prone to provide the best solution. If control strategy is to be utilized it should be considered as a design variable from the initial of the design. Only by using this approach maximum efficiency and cost reduction can be achieved.

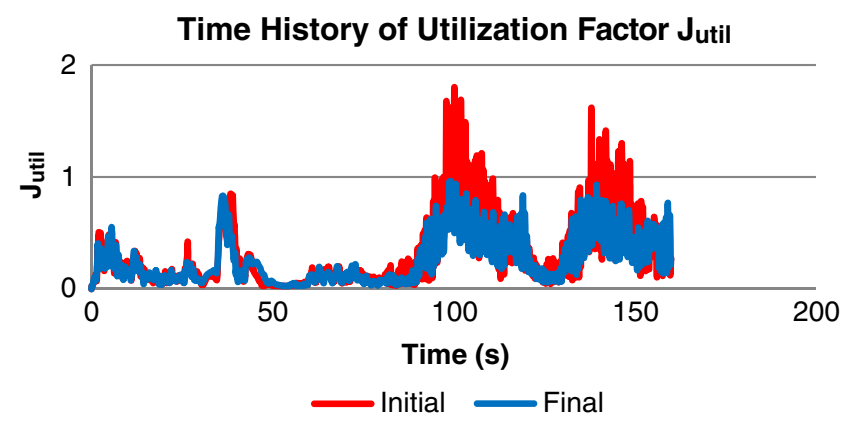

Fig. 18 Initial (red) and optimized time history utilization factor (blue)

Time History of Utilization Factor $J_{\text {util }}$ with no control

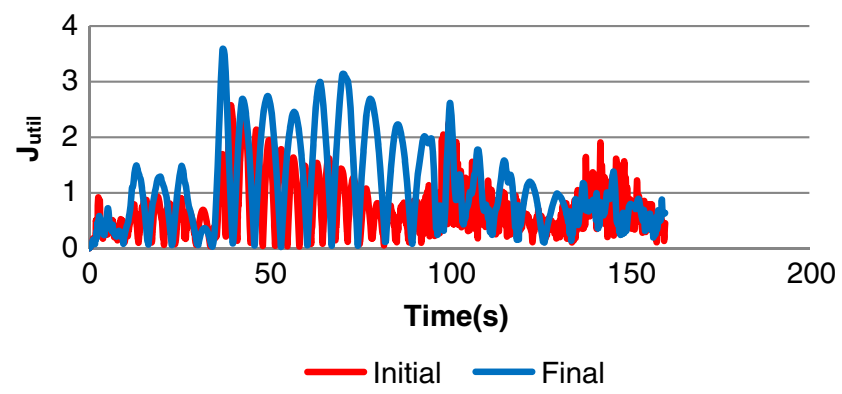

Fig. 19 Initial (red) and optimized time history utilization factor (blue) with no control devices 


\section{Conclusions}

In the traditional approach the structural model and control were separately optimized. This paradigm will no longer suffice to meet the demands of the high performance structures in the future. An integrated structure and control optimization is applied to a simplified model. It is acknowledged in the integrated design literature that the structure must be designed considering the control strategy a priori, or else the design solution is different and will not achieve the best performance. In the present work this is confirmed to be a very important issue in controlled cable stayed bridge design.

The optimization strategy and algorithm has been shown to be robust and efficient to determine the optimum design, reducing cost while dealing with large number of evaluation criteria and design variables.

The fan design proved to be more efficiently than the harp design in the numerical example. This new geometry allowed a cross section reduction and a most efficient control of the structure. The design variable V5 increased which would normally lead to higher demands on control devices (if the structure remains the same), nonetheless the control effort reduced which confirms that controllability of the structure was improved.

The control algorithm has proven to be efficient by reducing the bridge response, in particular in the optimized geometry. Sensor positioning, filtering and delay have proven to be suitable to determine control action and there was no considerable loss of performance moving away from the ideal control.

The time history analysis and master DOF location have proven to be particularly suitable for this purpose, increasing accuracy and reducing the optimization algorithm computation time.

The optimization algorithm here deals with the seismic loading. For a comprehensive design this algorithm needs to include more diverse type of loading (static, wind, erection stages, etc), structural non linearity, three dimensional properties and dynamic control devices. Cable pre-stressing, sensor positioning and control devices properties could also be considered as design variables.

\section{References}

Agrawal AK, Yang JN, He WL (2003) Aplications of some semiactive control systems to benchmark cable-stayed bridge. ASCE J Struct Eng 129(7):884-894
Cimellaro GP, Soong TT, Reinhorn AM (2008) Invited paper: optimal integrated design of controlled structures. In: Third international conference CIMTEC 2008 S.M.A.R.T. materials structures systems, Acireale, Sicily, Italy, 8-13 June

Cimellaro GP, Soong TT, Reinhorn AM (2009) Integrated design of inelastic controlled structural systems. Structural Control and Health Monitoring 16:689-702

Dutta AK, Dutta A, Deb S (2008) Design of an active controller for Quincy Bayview bridge, Illinois, U.S.A., against seismic excitation-Part II: control implementation. Structural Control and Health Monitoring 15:1078-1104

Dyke SJ, Caicedo JM, Turan G, Bergman LA, Hague S (2003) Phase I benchmark control problem for seismic response of cable-stayed bridges. ASCE J Struct Eng 129(7):857-872

Ferreira FLS, Simões LMC (2010) Optimum design of active and passive cable stayed footbridges. Computational Science Technology (CST2010)

Hafka RT, Gurdal Z (1992) Elements of structural optimization, solid mechanics and its application. Kluwer Academic Publishers, Netherlands

He W-J, Agrawal AK (2007) Passive and hybrid control systems for seismic protection of a benchmark cable-stayed bridge. Structural Control and Health Monitoring 14:1-26

Jaynes ET (1957) Information theory and statistical mechanics. Phys Rev 106:620-630, 108:171-190

Jung H-J, Spencer BF Jr, Lee I-W (2003) Control of seismically excited cable-stayed bridge employing magnetorheological fluid dampers. ASCE J Struct Eng 129(7):873-883

Khot NS (1998) Multicriteria optimization for design of structures with active control. J Aerosp Eng (ASCE) 11(2):45-51

Kirsch U (1993) Fundamentals and applications of structural optimization. Springer, Heidelberg, p 303

Magaña ME, Rodellar J, Casas JR, Mas J (1999) Active control of cable-stayed bridges. Smart Structures Conference 1999

Meirovitch L (1990) Dynamics and control of structures. WileyInterscience, New York

Messac A (1998) Control-structure integrated design with closedform design metrics using physical programming. AIAA J 36(5): $855-864$

Simões LMC, Negrão JH (1994) Sizing and geometry optimization of cable-stayed bridges. Comput Struct 52(2):309-321

Simões LMC, Negrão JH (1999) Optimization of cable-stayed bridges subjected to earthquakes with non-linear behavior. J Eng Opt $31: 457-478$

Simões LMC, Negrão JH (2005) Reliability optimum design of glulam cable-stayed foot-bridges. J Bridge Eng ASCE 10:39-44

Simões LMC, Templeman AB (1989) Entropy based optimization of cable net structures. Journal of Engineering Optimization 15: $121-140$

Spencer BF Jr, Nagarajaiah S (2003) State of art of structural control. ASCE J Struct Eng 129(7):845-856

Tzan SR, Pantelides CP (1996) Convex model for seismic design of structures-II: design of conventional and active structures. Earthq Eng Struct Dyn 25:945-963

Yang JN, Lin S, Jabbari F (2004) $H_{\infty}$-based control strategies for civil engineering structures. Structural Control and Health Monitoring 11:223-237, EN 1993-1 (Eurocode 3), EN 1998-1 (Eurocode 8) 